\title{
15 A Noble Art, and a Tricky Business
}

\author{
Translation Anthologies of Chinese Poetry
}

Maghiel van Crevel

\begin{abstract}
This essay suggests that in the early twenty-first century, Chinese-toEnglish presents a fascinating case study for the genre of the multipleauthor translation anthology - because of infighting on the Chinese poetry scene, foreign readers' unfamiliarity with this poetry, and profound changes in where the anthologists come from and what language they speak, with both questions taken in the broadest sense.
\end{abstract}

Keywords: Chinese poetry, translation, poetry anthologies, translation anthologies, non-native translators

Translation anthologists make very different books and say very different things about them. Let's consider some examples.

Yang Lian 杨炼, one of the editors of Jade Ladder: Contemporary Chinese Poetry, calls the anthology "a gathering of the best of Chinese poetry in the last thirty years" (Herbert et al. 2012, 41). In comparison, Liang Yujing's 梁 余晶 preface to his Zero Distance: New Poetry from China is low-key. Liang feels translation should prioritize "the young, the new and the unknown" $(2017,7)$, and paints his work as a translator as shaped by serendipity. And, he notes, "considering China's population and the number of poets, I will never say the poems in this book are the best I can find in China" (9). Brian Holton, co-editor and primary translator of Jade Ladder, cautions against solo translation by native Chinese speakers out of their mother tongue (Herbert et al. 2012, 351). Liang Yujing is a native Chinese speaker who solo-translates out of his mother tongue.

In In Your Face: Contemporary Chinese Poetry in English Translation, Ouyang Yu 欧阳昱 likens his work as editor and translator to "smuggling [the

Van Crevel, Maghiel and Lucas Klein (eds.), Chinese Poetry and Translation:Rights and Wrongs. Amsterdam: Amsterdam University Press, 2019

DOI: $10.5117 / 9789462989948 \_C H 15$ 
poems] into Australia as if they were illegal immigrants that this country never likes." But, he says, they will come in all the same, like "boatloads of people" have done, "whether you like it or not" $(2002,1)$. A decade later, in Breaking New Sky: Contemporary Poetry from China, rather than xenophobic chauvinists, Ouyang sees an audience of "Australian poetry lovers," to whom he promises "an eclectic selection of what are the most interesting, the most enticing, the most loveable poems, and the most controversial." They come from an ancient "poetry nation," and the anthology is "purely a labour of love" (2013, 9). In Your Face was privately funded. Breaking New Sky was funded by the Australian Council for the Arts.

In 1987 the Beijing-based Chinese Literature Press presented Julia Lin 林 明晖 with a collection of Chinese women's poetry and invited her to serve as its translator and English editor. Lin had moved from China to the US in 1949 to attend college and was professor of English at Ohio University. Her preface shows the work was completed in 1988, but Women of the Red Plain: An Anthology of Contemporary Chinese Women's Poetry was not published until 1992. Foreign distribution was by Penguin. Since the Chinese Literature Press must play by the rules of PRC cultural policy and propaganda, there is nary a word about June Fourth, the violent suppression of the 1989 Protest Movement that figures so prominently in early 1990 s foreign-produced anthologies of Chinese literature. That several authors are introduced by the Press as having "worked on the agricultural farms" squeezes another elephant into the room: the havoc of the Cultural Revolution (1966-1976), when countless urban youths were sent to the countryside. Lin's preface is brief, the author bios are written in Press officialese, and poets are listed alphabetically. One gets the sense that, beyond a gender-stereotyped Publisher's Note whose key assertion is that women write about feelings, the last thing the Press wanted to do, or wanted Lin to do, was to tell an actual story of modern Chinese women's poetry.

Almost twenty years later, Lin's Twentieth-Century Chinese Women's Poetry lists its contributors by birth year: poets from China in part I, overlapping with those featured in Women of the Red Plain but mostly represented by different texts, and poets from Taiwan in part II (2009). Her preface retains some passages from the 1992 anthology, for instance on her translational poetics, but she now speaks out on the significance of matters such as this poetry's feminist consciousness and its probing of the female psyche and sexuality. The contrast is thrown into even sharper relief by a thoughtful introduction by Lin and Nicholas Kaldis that does tell a story, with its origins in a draft by Lin that must go back to the late 1970s. Both anthologies are important books, but their maker finds herself in utterly different places in 1992 and 2009. 
The difference between Lin's two books foregrounds the impact of circumstance, which matters always. For the translation of poetry, circumstance includes everything from mass-media coverage of geopolitics - say, images of China in foreign newspapers - to the energy of small-press publishers that advance literary experiment.

But what anthologists do, and what they say they do, also reflects their individual agency and hence their positionality and their inclination. And notably, these things gain in significance in the case of contemporary mainland-Chinese poetry in translation, for three reasons. First, the foreign reader's unfamiliarity with this poetry. Second, the rapid increase of multilingualism in China and people's growing international mobility, with prominent roles for anthologists who hail from China and operate in English, in various places in the world. And third, the ways in which this poetry's sheer diversity and dynamism and its contestations inside China play out outside China.

What, then, are some of the salient issues that emerge from multipleauthor translation anthologies of contemporary mainland-Chinese poetry? ${ }^{1}$ Based on a lateral reading of about twenty such books published since the 1990s, I examine six monolingual specimens, whose primary intended readership is a general and not typically China-literate audience in the target culture, in loosely chronological order. I focus on paratext, a phenomenon whose importance for translation anthologies is well established. I privilege paratext of the kind that is part of the book in question - introductions, afterwords, author selection and sequence, bios, endorsements, and so on, also known as peritext - and only sporadically draw on the epitextual variety, in occasional references to book reviews.

\section{The genre, and the modern Chinese case}

In a study of Polish poetry in English translation, Bohdan Piasecki proposes a methodology for studying multiple-author translation anthologies (2010). He notes that as a relatively safe investment for the publisher, such anthologies constitute the vehicle of choice for foreign poetry. Indeed, for peripheral cultures and languages, he writes, they are often the only way for foreign poetry to reach its readers (9-10). (It is safe to say that modern Chinese

1 Bruno 2012 has an inventory for the years 1982-2009, also listing multiple-author books of greater scope in time and place, and single-author books. Later items are found in the MCLC Resource Center bibliographies. 
poetry remains peripheral vis-à-vis English and other European languages today, just like modern poetries in other non-European languages.) Piasecki further notes that translation anthologies tend to be taken as expressions of expert authority; and, at the same time, that the individual poems in them are subjected to triple decontextualization, from the individual author's oeuvre, their cultural milieu, and the source language (9). One might make that quadruple for anthologies with contributions by multiple translators, as distinct from the relative consistency one may expect in a single translator (or a single pair of translators working together), aside from the pros and cons of either situation. Piasecki concludes that translation anthologies afford maximum "opportunity for manipulation" (18) - in the translation studies sense of the word, not as a value judgment (e.g. Hermans 1985).

The anthologies discussed here show that in the case of contemporary Chinese poetry in English, opportunity for manipulation as an inherent condition of the genre is further expanded by the special significance of the anthologists' agency, positionality, and inclination. This makes for a variegated picture that defies easy categorization, also because individual anthologists engage in different ways with the demons that have haunted modern Chinese poetry from the start. These are classical Chinese poetry, (modern) foreign poetry, and something I abbreviate as "China," meaning a composite set of social and political realities that this poetry is often expected to reflect. Vis-à-vis the indigenous classics, modern Chinese poetry is widely considered to fall short. Vis-à-vis the foreign, it is regularly dismissed as imitative, no matter how often everyone reminds everyone else that, for instance, ur-Western-modernist Ezra Pound was inspired by premodern Chinese and Japanese poetry. And "China" rears its head, especially abroad, when poetry from the mainland is compulsively framed as being about its authors' native country and constituting political dissent.

\section{The changing of the guard}

The present essay follows on from a study by Cosima Bruno in which she shows that the paratextual message of three translation anthologies in the early 1990 s is marked by a politico-contextual focus of foreign discourse on contemporary Chinese poetry (2012, 264-268). The books in question are Edward Morin's The Red Azalea: Chinese Poetry since the Cultural Revolution (1990), Donald Finkel's A Splintered Mirror: Chinese Poetry from the Democracy Movement (1991), and Tony Barnstone's Out of the Howling Storm: The New Chinese Poetry (1993). Politicization of Chinese poetry - meaning 
overdetermination of this poetry as embodying dissent and resistance - is manifest in their titles, and has been ongoing ever since the emergence of Obscure Poetry (朦胧诗, sometimes also called Misty Poetry) in the journal Today (今天) in the late 1970s.

A change occurs when younger generations take center stage in translation anthologies. Wang Ping's 王屏 New Generation: Poems from China Today (1999) presents a transitional moment between Obscure poetry's nearmonopoly on foreign exposure and a more diverse, less politicized presence of Chinese poets in translation. As such, while her anthology contains much poetry written in the 199os, Wang's preface still dwells mostly on poetic trends and developments in the 1980s, the decade of high-culture fever (文 化热). At the same time, she clearly refers to the 1990s when she notes the "cynicism and materialism that have begun to emerge as part of Chinese life" and younger poets' "distaste for the relentless advance of capitalist mass culture" (24). More generally, the China demon rides again when she mostly contextualizes poetry in terms of social development. While Wang doesn't mention June Fourth, which was a powerful catalyst of change in Chinese poetry from one decade to the next, American poet John Yau's introduction to the volume uses June Fourth as its opening frame, and almost obsessively dwells on political repression, in a mismatch with the poetry it claims to introduce and with Wang's preface.

As regards Wang's positionality as editor and translator, key points include her personal trajectory and her method of translation. Her preface, author bio, and translator bio tell us she grew up in China and graduated from Peking University before moving to the US in 1985 and turning herself into a literary author publishing in English; New Generation originated in a Master's thesis in comparative literature at New York University, and the anthology's publication by the Hanging Loose Press was funded by the New York State Council on the Arts and the Fund for Poetry; and Wang produced the translations jointly with an impressive lineup of American poets, in what appears to have been an engaged, dialogic project with a native speaker of the source language at the center. Similar approaches would be followed by other anthologists in later years, sometimes also involving native-Anglophone scholars in addition to poets. Interestingly, Wang writes that the Chinese poets "speak to us as representatives of a country and culture very different from our own," thus identifying as American (29).

A prevalent typology of anthologies includes the general or survey type, which is the default type for anthologies of national literatures, with more or less explicit claims to representativeness; the special interest type - women's poetry, workers poetry, war poetry, and so on; and the programmatic type, 
which aspires to innovative intervention, for instance by launching a movement or supporting one among several competing poetics in a given literary field, and disrupting canonization rather than reaffirming it (Seruya 2013). Successful programmatic anthologies can become survey anthologies over time, and their distinction is complicated in interesting ways in translation anthologies, as we will see below, but it is safe to say that New Generation is of the survey type. It features twenty-four authors, sixteen men and eight women.

Assessing the representativeness of any multiple-author anthology is difficult. Doing so for contemporary Chinese poetry at any point since the mid-1980s is extra difficult in light of the flood waves of publications and the diversity and dynamism of the Chinese poetry scene. Still, New Generation definitely foregrounds important names and trends, although their interrelatedness is obscured by the alphabetical order in which the authors are presented. Sequencing poets by name disregards the cumulative, intertextual, constellational nature of literary production, and diminishes the potential of anthologies to create a whole greater than the sum of its parts and to let the decontextualized poems speak to one another in novel ways - an effect that can be enhanced in translation anthologies by the encounter with the target culture and its poetry. Sequencing poets by name suits reference works and readers who know what they are looking for, but for most anthologies it is arbitrary and arguably constitutes a forfeiture of editorial vision.

\section{Pushing your welcome abroad and fighting the canon back home}

Ouyang Yu trained in English and American literature in China in the late 1970 and early 1980 . This rendered the Chinese poetry of those years "totally unreadable and unlikeable" in his eyes $(2013,5)$. He moved to Australia in 1991 and has since become a prolific author and translator who publishes in English and Chinese and cultivates his status as enfant terrible of AustralianChinese literary encounters. His two translation anthologies, mentioned above, are remarkable in that they attack the reader in the target culture and the canon in the source culture, In Your Face mostly the former and Breaking New Sky mostly the latter.

In Your Face is a special issue of Otherland, a journal founded by Ouyang in 1994, and its physical qualities (paper, typography, layout) are clearly DIY. The introduction, named after Ouyang's image of poems as illegal immigrants, helps to establish a provocative discourse featuring a "thankless" Australian 
audience (Ouyang 2002, 1). They hardly "give a damn about poetry, still less about Chinese poetry," a claim Ouyang backs up by citing, as a badge of pride, his anthology's "saga of failure" (3) - meaning its rejection by multiple publishers. A quote by Ouyang Jianghe 欧阳江河 on the back cover adds a racial twist: "why have so many chinese migrated into english, / making an effort to become yellow-raced white people ...?” The introduction warns that those "who want to see the Western version of democracy and freedom here will be disappointed" (3), and that "there is something in me that refuses to be colonized by the West, epitomized by the very English language. Hence this anthology, to give back what has been rejected, in your face" (4).

After his provocation of the Australian and more broadly the Anglophone reader, Ouyang Yu explains his selection of source texts by pointing to the diversity and vitality of contemporary Chinese poetry. He advertises especially what I have called the earthly camp in this poetry - in opposition to the elevated camp, which we will encounter below - and its transgressive sides (van Crevel 2008, ch. 1; 2017, pars. 122-125). Among other things, he notes that the poems in In Your Face "are mildly and sensitively anti-Western" and "sexy" (Ouyang 2002, 2), which turns out to mean their subject matter includes sex work, as perceived by the consumer. As such, while the anthology features seventy-two authors of varying persuasion - all except two from mainland China, sixty-three male and nine female - it displays a partisan, programmatic orientation that explicitly directs foreign perspectives on Chinese poetry to particular factions on the domestic poetry scene. (This makes it all the more surprising that In Your Face, too, lists its authors in alphabetical order.) Ouyang takes a critical view of the canon, saying that "big shots" such as Bei Dao 北岛 "have been too well published and anthologized for me to bother" (2), his diction subverting a conventional discourse of the responsibility held by the anthologist. And indeed, there are some glaring absences that reaffirm Ouyang's pro-earthly and anti-elevated orientation: Zhai Yongming 翟永明 and Xi Chuan 西川, for example.

All anthologies have inherent (re)canonizing intentions and effects, whether the texts they contain count as canonical already or as "unknown, forgotten, marginalized" (Seruya 2013, 2). Translation anthologies may feature texts that have prior canonical status in the target culture - say, the so-manieth translation of Baudelaire into Dutch - as well as texts that are little known outside the source culture. Anthologization of the latter tends to rely heavily on source-culture canons, especially if the anthologists are native speakers of the target language and source and target language and culture are far apart. Most of the anthologies discussed here were compiled by native speakers of the source language instead, but it remains rare for 
a translation anthology to contest the source-culture canon as fiercely as Ouyang does.

Similar to In Your Face, Ouyang's 2013 anthology Breaking New Sky features a large number of poets in alphabetic order - forty-four contributors in all, thirty-three male and eleven female - but there is greater variation in the space allotted to individual poets, with woman poet Lu Ye 路也 out-paging everyone else. In his introduction, Ouyang looks back at a decade of teaching poetry translation in Melbourne. He senses that there is a change in the air because his students, who are not poetry experts, display a "sensitive, versatile and down-to-earth" taste and "avoid anything big-sounding or lyrically obscure" (5). What they get to see is, of course, what their teacher wants them to see, and Ouyang explains that he starts by showing them a selection of poems he likes.

Ouyang links his students' stylistic preferences to ongoing contestations of the canon in the source culture. Expressing frustration with the mainstream habit of enumerating accolades in author bios, he says the Chinese poetry scene is now home to "a democracy of poetic voices that are outside official fame and status" (6). And true enough, Breaking New Sky contains work by many young authors who are not among the regular fare presented in high-profile Chinese-language anthologies. However, they appear alongside several older, über-canonized poets from the mainland and Taiwan. Also, while some of the author bios are of the impish kind - Zhang Zixuan's 张子 选 simply reads "Zhang Zixuan is a stranger to me" (121) - many are filled with the accolades Ouyang so despises, introducing authors rather tiredly as "widely published" and the recipients of various poetry prizes, a commodity that has proliferated in China in the last two decades.

In all, to this reader - who is not its primary intended, non-China-literate reader - the introduction is an unconstrained piece that cuts itself loose from what is by now a richly documented history of the Chinese poetry scene since the Cultural Revolution. Ouyang's story begins, for instance, with his disdain for the official poetry of the Maoist years but then fast-forwards to the early twenty-first century, blotting out the explosion of poetic development in the 1980s and 1990s. This may explain why, in an endorsement on the back cover, Australian poet Brian Castro claims that the anthology "marks a sea-change in the form" and "exhibits a liberating, existential dimension previously constricted by propaganda and self-censorship." Castro's statement is misguided, and it sustains the foreign politicization of Chinese poetry.

Of course, Ouyang has never claimed, and has in fact consistently disclaimed, representativeness and responsibility. More generally, assessing 
a translation's "fidelity" is as problematic for a book-length anthology as it is for a single word. On that note, Castro praises Ouyang's method of "direct translation," which Ouyang says is "a way of translating the words or expressions as they are, in the original" rather than matching them with "something roughly equivalent in the target language." This, he says, "results in poetry that fills the lacuna of a target language" with something "so quotidian in the source language, that one's sense is numbed, adding strangeness to the beauty of the translated poem." As an example, he cites “windscape” for 风景, usually rendered as “landscape" (9-10). In all, his method appears to revolve around literalness, and to aim at defamiliarization and foreignization. It has met with critical responses (e.g. Ferney 2014) and sympathetic ones (e.g. Harvey 2015).

\section{Imperfection}

This takes me to what I will call the legitimacy of non-native linguistic "imperfection." I am not a native speaker of English myself, so I may be out of my depth here (which might make the argument recursive in interesting ways). The issue is linked to the ever-growing problem of the hegemony of English in world literary discourse, but it is worth asking if it also occurs in other languages. In the present context, it arises from the observation that while Ouyang Yu's command of English is phenomenal, his translations and their paratexts regularly contain turns of phrase that a native speaker would not use.

I am, needless to say, not implying that in a given discursive situation, all native speakers will use the exact same words; or that linguistic nativeness and foreignness are self-evident, stable, or unproblematic categories, a myth dispelled in different if related contexts by Jing Tsu and Rey Chow in their discussions of the Chinese diaspora (Tsu 2010) and postcoloniality (Chow 2014). Nor am I referring to imperfection, and related notions such as failure, as instances of willed foreignization à la Venuti (2018), where the translator intentionally makes themself and the translation visible in areas such as the lexicon, syntax, rhetoric broadly defined (including imagery), and more generally the linguistic reflection of social norms and values. Willed foreignization, or the refusal to nativize, sets out to challenge mainstream tropes for successful translation such as fluency, transparency, seamlessness, and so on - tropes that are quite literally utopian, in their denial of the source text as a place of its own - in order to resist the tyranny of the target language and its (translation) culture. See, for instance, Jenn Marie Nunes's 
engagement with Yu Xiuhua's 余秀华 poetry in this book; and Madhu Kaza's advocacy of immigrant and diasporic approaches summed up in the image of "kitchen table translation" (2017); and the discourse surrounding "ethnic" Englishes - or Frenches, or Chineses, and so on.

Rather, I mean ever so slightly "off" usage that looks like it is unintentional, often surrounding little things whose elusiveness is well known to foreign language learners who do in fact aspire to some kind of standard proficiency or mastery. Think articles, particles, prepositions, punctuation, verb tense and mode, singular and plural forms; and, more generally, the unspectacular idiomaticity and the subtle navigation of linguistic register and collocation that glue such native usage together. There are several instances of such deviation from the native norm in Ouyang's words as cited in the preceding pages. In the final paragraph of the previous section, for instance: "fill the lacuna of a target language" and the comma after "so quotidian in the source language."

Why am I making this point? Not, obviously, to reinstate the simplistic notions of "right" and "wrong" that this book critiques, in regard to translation or to linguistic usage at large. I am making this point because it forces us to revisit the dogma, or the rule, or the expectation, or the memory, that says literary writing does not allow for imperfection of this kind - or to reaffirm this as a misconception. Of course, the publishing business is marked by anarchy in comparison with just a few decades ago; and copy-editing is not what it used to be; and there are multiple Englishes; and the downside of hegemony is that everyone has access to what was once your language and can mess with it. But who says you cannot say "fill the lacuna of a target language" instead of, for instance, "fill lacunae in the target language," even if this deviation from a more or less consensual native norm is unintentional? And who is "you" in this statement? The native speaker, for sure, but what about the foreign speaker who solo-translates out of their mother tongue, in Holton's words, or solo-writes in a foreign tongue?

In any event, what Ouyang has called his refusal to be colonized by the West as epitomized by the English language makes it likely that he would reject the "correction" of his "errors" - even if he might resolve not to make the error in question again. Scare quotes, not because I believe either notion has lost its purchase in literary writing but because it appears reasonable to assume that even as Ouyang continues to work toward the perfection of his English, he is well aware of its imperfection - and not worried about it.

But this is not merely, or even primarily, about Ouyang Yu. Who else might be not worried, in which constellations of languages and cultures? Does imperfection work the same for Baudelaire in Dutch as for contemporary 
Chinese poetry in English? I suspect there would be little tolerance for imperfection in the former case. Aside from the question of whether this should elicit boos or cheers, what might it tell us about the issue more broadly? Acceptance can signal a willingness to decenter normativity, as in Dimitra Harvey's review of Breaking New Sky (2015), although she focuses on imagery rather than native-usage glue; and this willingness may stem, in part or in whole, from the sense that when a language becomes a world language, it also becomes common property. But acceptance can also signal indifference - and might this be more likely when the source language is peripheral in the literary system? Lucas Klein has asked whether anthologies of Chinese poetry in translation "expand the field of American poetry, or exist at a sequestered, even ghettoized remove" (2011). The question is at once activist and rhetorical.

\section{Not just the poetry but also the polemics}

If Ouyang's anthologies are partial to the earthly camp on the domestic Chinese poetry scene, three big anthologies published in the US between 2007 and 2013 are similarly programmatic in their preference for the elevated camp. This shows in their selection of authors and in the discourse of their introductions. In other words, partisan positionings on the Chinese-domestic poetry scene are transplanted to translation anthologies. From a theoretical perspective, this is noteworthy in that it undercuts the genre's conventional association with the survey type rather than the programmatic type, discussed above.

The books in question are Zhang Er 张耳 and Chen Dongdong's 陈东东 Another Kind of Nation: An Anthology of Contemporary Chinese Poetry (2007), Wang Qingping's 王清平 Push Open the Window: Contemporary Poetry from China (2011), and Ming Di's 明迪 New Cathay: Contemporary Chinese Poetry (2013). These three books clock in with male and female authors at sixteen to eight, forty-two to seven, and nineteen to six, respectively (but an actual page count reduces female-authored poetry in New Cathay to one seventh of the book). All three were edited by native speakers of Chinese and translated by multiple scholars and poets, with native speakers of English in the majority, Push Open the Window mostly in single-translator projects and the other two books in collaborative ones.

Here I will focus on the monolingual New Cathay (the other two books include the Chinese source texts), which was published by Tupelo Press with support from the Harriet Monroe Poetry Institute of the US-based 
Poetry Foundation. Editor Ming Di's trajectory is similar to that of Wang Ping and Ouyang Yu. She was born and grew up in China, did graduate studies in linguistics at Boston University, and is resident in the US, while continuing to visit China regularly for collaborative projects. A two-way literary translator of Chinese and English, she is an internationally active contributor to academic and cultural exchange, and is affiliated with poetry festivals in Rotterdam and Berlin.

The transplantation of domestic issues to translation anthologies can wear the guise of best-of representativeness - which holds for Another Kind of Nation and Push Open the Window, even though the specialist will spot the markers of their partisanship - or it can happen in full view, as in Ouyang's anthologies, and in New Cathay. In the rift between earthly and elevated aesthetics in Chinese poetry that culminated in the 1998-20oo polemic of so-called Popular (民间) and Intellectual (知识分子) writing, Ming Di explicitly sides with the elevated and the Intellectual. As such, it makes sense that she presents this poetry's encounter with Western modernism in highly positive terms; by contrast, Popular voices have accused it of selling out to the West. Remarkably, Ming Di also says the Intellectuals "have been underrepresented in studies of Chinese poetry" (2013, xvi). This is untrue - it was at the time and remains so today - and many would hold that the opposite is true.

I have noted that modern Chinese poetry continues to be haunted by its classical forebears. But in Chinese-domestic discourse in the new century, this poetry's relation to the classics has also been portrayed as an asset - and it appears as such in translation anthologies as well. In Another Kind of Nation, Zhang Er links contemporary poetry to aesthetic, metaphysical, and linguistic-philosophical notions rooted in ancient Chinese culture, in somewhat exoticizing fashion (2007, 3, 6-8; like Wang Ping, Zhang Er identifies as American: "By looking at them, we look at our own world and ourselves" [5]). And in New Cathay, contemporary poetry's relation to the classical tradition is the opening shot. Ming Di writes that in the 1990s and 2000s, after many years of influence from the West, the poets "have been trying ... to 'return' to ancient literary traditions." What does this actually mean? Rather than writing poetry the way it was written in the past, she says, they "adopt a classical 'spirit' in perspectives and emotional appeals" (2013, xiii).

She later returns to the issue, but without textual evidence beyond the assertion that Duo Duo's 多多 “repetition of adverbials is a re-creation of repeated patterns in ancient poetry" (xvi). Citing a Chineseness that "traces back to ancient tradition," she declines to define this and instead invites the reader to discover it for themself (xxi-xxii). In all, New Cathay takes domestic 
debate on contemporary poetry's relation to classical poetry straight to the foreign audience, but it does so in a claim that comes across as wishful, and less substantiated than might be required in Chinese-language discourse.

\section{Climbing between earth and heaven}

Contemporary poetry's relation to classical poetry is also addressed in Jade Ladder: Contemporary Chinese Poetry, cited at the beginning of this essay. Edited by Scottish poet W. N. Herbert and Chinese poet Yang Lian with Chinese-English and Chinese-Scots translator Brian Holton and Chinese poet and critic Qin Xiaoyu 秦晓宇, this anthology was published by Bloodaxe in the UK with support from the Arts Council England (2012). It has an abundance of explicit paratext by all four editors, and its implicit paratext includes the selection of fifty male and three female poets. This latest in a series of head counts I have included for each anthology is an extreme example of how translation anthologies mirror a deeply disturbing male dominance on the Chinese poetry scene (van Crevel 2017, pars. 13-20 and 95-97). Of the four reviews of Jade Ladder I have seen, the only one to note this - and the only female-authored - is that by Liansu Meng (Burnhope n.d., Radford 2013, Taylor 2013, Meng 2015).

Yang's introduction positions all of Chinese poetry in a lineage going back over two millennia and says contemporary poets are "watched," as in monitored by authority figures, by classical greats Qu Yuan 屈原 and Du $\mathrm{Fu}$ 杜甫 (Herbert et al. 2012, 42). Qin discusses classical presences in the contemporary in more detail, in his introductions to sections in the book that are dedicated to lyric poems, narrative poems, neo-classical poems, sequences, experimental poems, and long poems. The category of the lyric is taken broadly and Qin barely broaches the question of its applicability to poetry written in antiquity and poetry written in the twenty-first century, or the question of how Chinese and English notions of the lyric relate. While he offers more textual evidence for contemporary engagement with indigenous traditions than do Zhang Er and Ming Di, the discussion remains limited to a very small number of poets (mainly Zhang Zao 张冭) and is conducted at a high level of abstraction. Qin's discussion of narrativity (215-216) is not immediately convincing when he suggests kinship between classical forms such as Music Bureau poetry (乐府) and the narrative poetry (叙事诗) of the 1990s (see van Crevel 2008, ch. 8).

Jade Ladder exudes a solemn ambition. As Yang explains, its title refers to a vision of the mythical Mount Kunlun as a ladder that "the holy could climb 
between earth and heaven" (Herbert et al. 2012, 32). Herbert calls the ladder a symbol for "the transit of the Chinese poem between the imagination and the world" (17). He says that on contemporary Chinese poetry, "for the [Anglophone] general reader, for the student or even the teacher, there are few authoritative resources available" (19), and this is the gap Jade Ladder wants to fill. Critical of anthologies to date, he finds "the point of finish" of most Chinese poetry in translation "premature" (22), and wonders what Chinese poets "think about their representation in translation in the West" (20). Accordingly, he sets great store by a critical, multiple-actor translation method involving "poet-to-poet" translation (21).

Herbert, who has made multiple visits to China since the mid-20oos, is aware of the diversity and dynamism of the Chinese poetry scene. He speaks of "one of the world's most thorough and exciting experiments in contemporary poetry" (17). At the same time, just like Brian Castro, he falls prey to familiar patterns of foreign politicization of this poetry when he praises what it has "achieved in the face of much oppression and official constraint" (22). Censorship remains forcefully operational in China, but oppression and constraint are certainly not the first things that the bustling poetry scene of the past forty years brings to mind.

Another misrepresentation occurs when Yang writes that Jade Ladder attempts to present "a complete picture of the complex and exciting events which have been unfolding in contemporary China," and "locate this in the depths of its poetry" (41). In Paul Barnaby's words, this would make it the type of anthology that wants to offer "a state-of-the-nation survey or potted social history of the source culture" $(2002,86)$. But this goal remains out of reach, for two reasons. First, it clashes with the anthology's professed aim to present the poetry with full respect for the autonomy of the artwork, or indeed with this autonomy as its point of departure. Witness, among other things, the pointed absence of biographical information on the poets, a standard feature of the other anthologies sampled for this essay.

Second, Jade Ladder overwhelmingly features poets who rose to prominence in the 1980 s and the 1990s, and hardly any poets who emerged in the 200os - when new poetic trends continued to proliferate and the internet and social media added an entirely new dimension to the poetry scene that is aesthetic as well as social in nature (Inwood 2014). Yang's general introduction is memoir-like and dwells at length on the 1980s and on exile poetry after June Fourth, and its attention to older generations drowns out Qin's notes on more recent developments.

In a related point,Jade Ladder's overbearing allegiance is with the elevated pole on the wide aesthetic range of contemporary Chinese poetics. This is 
not counterbalanced by the inclusion of two unignorable representatives of the earthly camp, Yu Jian 于坚 and Yi Sha 伊沙 (Han Dong 韩东 should have been equally unignorable, but is ignored nonetheless). In all, precisely because Jade Ladder aspires to be comprehensive and authoritative, its bias in the interrelated areas of gender, generation, and aesthetics is all the more conspicuous.

In regard to translation method, the emphasis in Jade Ladder on bilingual collaboration and the involvement of poets in addition to those who primarily identify as translators recall Wang Ping's, Zhang Er and Chen Dongdong's, and Ming Di's anthologies, but there is a difference - which constitutes, at the same time, a similarity with the early 1990 anthologies edited by Morin, Finkel, and Barnstone reviewed by Bruno. W. N. Herbert, the ultimate arbiter of the poetry collected in Jade Ladder, is a native speaker and poet of the English language; and the primacy of poetic, native-normative English is reaffirmed by the central translator, Brian Holton.

Jade Ladder ends with Holton's "Phrases That Shall Be Musical in the Mouth," an essay that shows him as deeply committed to, and highly demanding of, the translation of (Chinese) poetry, and as opinionated and polemical. I quote at length to zoom in on an issue that recurs throughout the present essay:

And here I must address native Chinese translators: substituting English dictionary definitions for Chinese words does not make a poem ... The idea is still current in China that, since non-native speakers cannot read Chinese with the necessary sensitivity to nuance, then all translations of China's astonishingly diverse and accomplished literature should be done by Chinese people only ... The first part of that statement is perfectly true ... To state, however, that only Chinese people should translate out of their mother tongue ... is, quite simply, nonsense. Of all the millions of Chinese speakers of English, only a vanishingly small proportion have mastered the language to the point where they can produce literary texts of any quality. The vast majority of Chinese-English literary translation simply does not work, because fluency is not at all the same as mastery ... If you're Chinese and want to translate Chinese poetry ... then you only need one thing, and that is a collaborator with a high level of competence as a writer who is a native speaker of your target language ... non-native versions rarely work as poetry: the non-native can never see the text in the same way as the native speaker - in effect, they are reading different poems, as each brings a different set of values and expectations to the text, and the text can't not be read through the lens of these values and 
expectations. This, in our case, is an unavoidable result of the gap between the cultures of China and the cultures of the English-speaking world.

(Herbert et al. 2012, 351-352)

There is some rhetorical flourish here. Also, I dispute that, in the places where it matters, the idea is current that translation from the Chinese must only be undertaken by native speakers of Chinese. More interesting is that Holton touches only fleetingly on what I have called linguistic imperfection, in his reference to mastery (which, if you think about it, is a concept whose routine conjunction with a "native" language is strange, and indeed disturbing in its conjunction with foreign languages, in the context of colonialism and otherwise). And, conversely, that he invokes cultural difference to explain his assertion that non-native versions rarely work as poetry. Venuti posits the need to recognize cultural difference as always unapologetically operational in translation, and as anything but the disqualifying force Holton makes it out to be. This has helped to establish a vision of (poetry) translation that sheds hierarchical thinking about the source text as originary and the translation as derivative. Especially because Holton subscribes to this vision (353-354), his depiction of cultural difference as a "gap" that produces "unavoidable results" is surprising.

\section{No one cares}

I began this essay by contrasting Jade Ladder with Zero Distance: New Poetry from China, and will end by showing that the differences between these two books extend to every dimension. Liang Yujing, the editor and solo translator of Zero Distance, is a native speaker of Chinese, born in China and trained there in English literature. He began writing poetry in English in 2008. Like several of the other anthologists whose work I have considered above, he is a two-way literary translator of Chinese and English. He moved to New Zealand in 2014 and, at this writing, is doing $\mathrm{PhD}$ research on contemporary Chinese poetry there. That there is "imperfection" in his English usage has not kept him from publishing authored and translated poetry in various journals in the Anglophone world.

Zero Distance was published in 2017 with support from the Hawai'i Community Foundation by Tinfish Press, a not-for-profit publisher dedicated to experimental poetry from the Pacific region with other Chinese poetry projects to its name. It contains the work of twenty-nine authors. Most were born in the 1980 s or 1970s, are little known beyond the in-crowd, and 
are very much part of trends and developments in the 2000s and 2010s. The anthology's orientation is on the earthly and transgressive side of things, and Yi Sha and Ouyang Yu are included as patron saints from older generations. "Zero Distance" is the name of a poem by Ouyang, and Liang cites Ouyang's notion of direct translation and Yi Sha's Poetry Canon for the New Century project (新世纪诗典) (7; see van Crevel 2017, pars. 127-136). At twenty male to nine female authors, the anthology does better than most for gender balance, but Liang is not satisfied with the numbers and identifies male dominance as a problem on the Chinese poetry scene, recalling how a woman poet withdrew her work for fear it might "bring her trouble" (Liang 2017, 8). He ends a nutshell history of contemporary Chinese poetry by saying that, "to some extent, poetry has become the freest form of literature in China," and that this is because "no one cares" (6). Rather than a lament, this comes across as a celebration of the space and the style Liang appropriates, as an anthologist who sits squarely in the twenty-first century.

\section{What's new?}

Some things never change. Modern Chinese poetry's three demons have haunted translation anthologies starting with Harold Acton and Ch'en Shih-hsiang's 陈世骧 (1936) and Robert Payne's (1947) books. So has the male dominance that has marred the modern poetry scene from the beginning: a fourth demon, albeit one who operates throughout the world. Acton and Ch'en's and Payne's anthologies are all-male, and Payne calls the “sentimentality" of some of the New Poetry (新诗) “excusable” in Bing Xin 冰心, “who was after all only a woman" (13).

But other things do change, and on balance, anthologies of contemporary Chinese poetry in English translation have changed a great deal in recent decades. Against the background of transformations in Chinese society and Chinese-foreign relations at every level from geopolitics to individual identity, there has been a notable diversification in where the anthologists come from, literally and otherwise, as well as in the body of texts on which they draw, born of a poetry scene in relentless tumult. This is an intersectional process that mobilizes multiple axes of positionality: Chinese and English nativeness and foreign literacy, age, gender, individual and collective experiences of the presence of politics in literature, local and international networks, allegiance to particular camps in source-culture poetics, translation methods, institutional affiliations and resources. And: various perspectives on modern Chinese poetry's demons. 
Speaking of which... in a rich, critical essay on the translation and introduction of this poetry in the US, written in Chinese and published in China, Ming Di says that Chinese poets ought to be thinking about what is "poetically special about contemporary Chinese poetry that could truly raise Western poets' interest." But then she catches herself and adds in the same breath that of course, "Chinese poetry has its own development, and need not deliberately change for the outside world" (2015, 72-73).

Contemporary Chinese-English translation anthologies embody the encounter of outside narratives and inside stories, and the complexity of that encounter.

\section{Works cited}

Acton, Harold and Ch'en Shih-hsiang, trans. 1936. Modern Chinese Poetry. London: Duckworth.

Barnaby, Paul. 2002. "Scotland Anthologised: Images of Contemporary Scottish Identity in Translation Anthologies of Scottish Poetry." The Scottish Review 3 (1): 86-99.

Barnstone, Tony, ed. 1993. Out of the Howling Storm: The New Chinese Poetry. Hanover: Wesleyan University Press.

Bruno, Cosima. 2012. "The Public Life of Contemporary Chinese Poetry in English Translation." Target 24 (2): 253-285.

Burnhope, Mark. N.d. Review of Herbert et al. 2012. Magma Poetry, no date. bit.ly/ ${ }_{2} \mathrm{G}_{2} \mathrm{lYxf}$. Accessed April 1, 2018.

Chow, Rey. 2014. Not Like a Native Speaker: On Languaging as a Postcolonial Experience. New York: Columbia University Press.

Ferney, Liam. 2014. Review of Ouyang 2013. Rabbit 12: 118-124.

Finkel, Donald, trans. 1991. A Splintered Mirror: Chinese Poetry from the Democracy Movement. San Francisco: Northpoint Press.

Harvey, Dimitra. 2015. Review of Ouyang 2013. Mascara, May 25. bit.ly/2OX6jDD. Accessed April 1, 2018.

Herbert, W. N. and Yang Lian with Brian Holton and Qin Xiaoyu, eds. 2012.Jade Ladder: Contemporary Chinese Poetry. Tarset: Bloodaxe.

Hermans, Theo, ed. 1985. The Manipulation of Literature: Studies in Literary Translation. London: Croom Helm.

Inwood, Heather. 2014. Verse Going Viral: China's New Media Scenes. Seattle: University of Washington Press.

Kaza, Madhu, ed. 2017. Kitchen Table Translation. Special Issue of Aster(ix) Journal, July 2017. 
Klein, Lucas. 2011. "Anthologies and Anthologies." Blog post, Notes on the Mosquito: A Blog on Xi Chuan and Chinese Poetry in English Translation, December 10. bit.ly/2KgtiL8. Accessed April 1, 2018.

Liang Yujing, ed. and trans. 2017. Zero Distance: New Poetry from China. Kāne'ohe: Tinfish.

Lin, Julia C., ed. and trans. 1992. Women of the Red Plain: An Anthology of Contemporary Chinese Women's Poetry. Beijing: Chinese Literature Press, and London: Penguin Books.

-, ed. and trans. 2009. Twentieth-Century Chinese Women's Poetry: An Anthology. Armonk: M. E. Sharpe.

Meng Liansu. 2015. Review of Herbert et al. 2012. MCLC Resource Center. bit.ly/ 2U6FLRp. Accessed April 1, 2018.

Ming Di, ed. 2013. New Cathay: Contemporary Chinese Poetry. North Adams: Tupelo Press.

一明迪. 2015.〈影响与焦虑: 中国当代诗在美国的译介状况〉 [Influence and anxiety: the introduction and translation of contemporary Chinese poetry in America]. In《他者眼光与海外视角: 世界视野中的中国当代文学》 [The gaze of the Other and foreign perspectives: contemporary Chinese literature in the eyes of the world], edited by Zhang Qinghua 张清华. Beijing: Beijing daxue chubanshe.

Morin, Edward, ed. 1990. The Red Azalea:Chinese Poetry since the Cultural Revolution. Honolulu: University of Hawai'i Press.

Ouyang Yu, ed. and trans. 2002. In Your Face: Contemporary Chinese Poetry in English Translation. Otherland 8.

—, ed. and trans. 2013. Breaking New Sky: Contemporary Poetry from China. Parkville: Five Islands Press.

Payne, Robert, ed. 1947. Contemporary Chinese Poetry. London: Routledge.

Piasecki, Bodham Andrzej. 2010. "Anthologies of Contemporary Polish Poetry in English Translation: Paratexts, Narratives, and the Manipulation of National Literatures." PhD dissertation, University of Warwick.

Radford, Andrew. 2013. Review of Herbert et al. 2012. Translation and Literature 22: 142-148.

Seruya, Teresa. 2013. "Anthologies and Translation." In Handbook of Translation Studies: Volume 4, edited by Luc van Doorslaer and Yves Gambier, 1-6. Amsterdam: John Benjamins.

Taylor, John. 2013. Review of Herbert et al. 2012 among other books. The Antioch Review, March 1: 382-389.

Tsu, Jing. 2010. Sound and Script in Chinese Diaspora. Cambridge, MA: Harvard University Press. 
van Crevel, Maghiel. 2008. Chinese Poetry in Times of Mind, Mayhem and Money. Leiden: Brill.

- 2017. "Walk on the Wild Side: Snapshots of the Chinese Poetry Scene." MCLC Resource Center. bit.ly/2GaWWhc. Accessed April 1, 2018.

Venuti, Lawrence. 2018. The Translator's Invisibility: A History of Translation, third edition. New York: Routledge.

Wang Qingping, ed. 2011. Push Open the Window: Contemporary Poetry from China. Port Townsend: Copper Canyon Press.

Wang Ping, ed. 1999. New Generation: Poems from China Today. New York: Hanging Loose Press.

Zhang Er and Chen Dongdong, eds. 2007. Another Kind of Nation: An Anthology of Contemporary Chinese Poetry. Jersey City: Talisman House.

\section{About the author}

Maghiel van CREVEL is professor of Chinese language and literature at Leiden University. A specialist of contemporary poetry, he has published a dozen books in English, Dutch, and Chinese, including scholarly monographs and edited volumes, literary translations, and language textbooks. His research draws on extensive fieldwork undertaken since the early 1990s. See, for instance, the long essay "Walk on the Wild Side: Snapshots of the Chinese Poetry Scene" (2017), downloadable at the MCLC Resource Center. 